\title{
Evaluation of Nitrogen Conversion Ratio on Reaction between BN and Aluminum
}

\author{
Makoto Kobashi, Kenzo Saiki* and Naoyuki Kanetake \\ Department of Materials Science Engineering, Graduate School of Engineering, Nagoya University, Nagoya 464-8603, Japan
}

The fundamental reaction behavior between aluminum powder and boron nitride (BN) powder was investigated, and a quantitative evaluation of aluminum nitride (AIN) formation was carried out. As a result of differential scanning calorimeter (DSC) analysis, an exothermic reaction between $\mathrm{BN}$ and aluminum was detected at temperatures between 1073 and $1173 \mathrm{~K}$. The conversion ratio of $\mathrm{BN}$ to $\mathrm{AlN}$ increased with increasing heating temperature. However, the nitrogen conversion ratio appeared to saturate with a holding time of $3.6 \mathrm{ks}$ at temperatures above $1273 \mathrm{~K}$. The nitrogen conversion ratio increased by using $1 \mu \mathrm{m} \mathrm{BN}$ powder instead of $10 \mu \mathrm{m}$ BN powder. The effect of using the fine BN powder was significant especially when the heating time was short $(<300 \mathrm{~s})$. [doi:10.2320/matertrans.M2011184]

(Received June 17, 2011; Accepted July 19, 2011; Published September 7, 2011)

Keywords: aluminum, boron nitride, aluminum nitride, nitrogen conversion ratio, ceramics matrix composite

\section{Introduction}

Among several kinds of ceramics, aluminum nitride (AlN) is noted for its excellent properties such as a high thermal conductivity, high-temperature mechanical properties, and low dielectric constant. ${ }^{1-4)}$ However, a high sintering temperature is regarded as a serious disadvantage for this material. Since AlN is a covalently bonded material, it has a low diffusivity and requires high temperatures $(\sim 2200 \mathrm{~K})$ and a long heating period $(3-8 \mathrm{~h})$ for densification. ${ }^{5-9)}$ Another disadvantage is that AlN exhibits a low fracture toughness and has not, therefore, been considered as a candidate material for structural applications. However, the fracture toughness of AlN can be improved by dispersing hard second phases such as titanium boride $\left(\mathrm{TiB}_{2}\right)$ particles in the material. ${ }^{10-12)}$ The authors have investigated a reactive processing technique for producing $\mathrm{TiB}_{2}$ dispersed $\mathrm{AlN}$ composites with the help of a reaction between aluminum, titanium, and boron nitride (BN) as shown in the following equation. ${ }^{13-16)}$

$$
2 \mathrm{Al}+2 \mathrm{BN}+\mathrm{Ti} \rightarrow 2 \mathrm{AlN}+\mathrm{TiB}_{2}
$$

In previous research, ${ }^{16)}$ we found that the reaction between aluminum and $\mathrm{BN}$ was a dominant factor which controlled the conversion behavior of $\mathrm{BN}$ to $\mathrm{AlN}$, and the conversion ratio was strongly affected by the heating temperature. Therefore, fundamental research focusing on the reaction between aluminum and $\mathrm{BN}$ is essential. In this paper, compacted powder blends consisting of aluminum and $\mathrm{BN}$ powders were prepared, and a quantitative analysis of the reaction product after heat treatments was carried out to determine the effects of important processing conditions (heating temperature, holding time, and $\mathrm{BN}$ powder size) on the conversion behavior of $\mathrm{BN}$ to $\mathrm{AlN}$.

\section{Experimental Procedure}

Starting materials used in this experiment were aluminum powder (size: $<45 \mu \mathrm{m}$, purity: $99.8 \%$ ) and BN powders ((1)

*Graduate Student, Nagoya University. Present address: IBIDEN CO., LTD., Ibigun 501-0695, Japan size: under $1 \mu \mathrm{m}$, purity: $99.5 \%$; (2) size: $10 \mu \mathrm{m}$ average, purity $99.9 \%$ ). First of all, aluminum and BN powders were blended with an $\mathrm{Al} / \mathrm{BN}$ molar blending ratio of 3.0/2.0. The blended powder $(2.5 \mathrm{~g})$ was then compressed under a pressure of $200 \mathrm{MPa}$ to make a compacted powder preform (cylindrical shape: $\varphi 10 \mathrm{~mm} \times 15 \mathrm{~mm}$ height), and this is denoted as the $[\mathrm{Al}+\mathrm{BN}]$ preform in this paper. The $[\mathrm{Al}+\mathrm{BN}]$ preform was inserted into an $\mathrm{Al}_{2} \mathrm{O}_{3}$ crucible and placed in an infrared furnace. The preform was heated at a rate of $1.0 \mathrm{~K} \cdot \mathrm{s}^{-1}$ to various predetermined temperatures (1073$1673 \mathrm{~K})$ in an Ar atmosphere and held at the designated temperature for $0-3.6 \mathrm{ks}$. The cross section of the specimen was analyzed by X-ray diffraction (XRD). The quantitative analysis of the reaction product was carried out by a calibration curve method. The calibration curve was obtained from the XRD data of AIN and BN powder mixtures (where the $\mathrm{AlN} /(\mathrm{AlN}+\mathrm{BN})$ molar ratio was varied from 0.1 to 0.9$)$.

Figure 1(a) shows the XRD data for preparing the calibration curve. The integrated intensity $(J)$ of $(002)$ peak of BN and the (100), (002), (101) peaks of AlN were measured from the XRD data, and $J_{\mathrm{AlN}}$ and $J_{\mathrm{BN}}$ were derived by the following equations:

$$
\begin{aligned}
& J_{\mathrm{AlN}}=J_{\mathrm{AlN}(100)}+J_{\mathrm{AlN}(002)}+J_{\mathrm{AlN}(101)} \\
& J_{\mathrm{BN}}=J_{\mathrm{BN}(002)}
\end{aligned}
$$

Figure 1(b) shows the calibration curve obtained from the $\mathrm{XRD}$ data. In this paper, the mole fraction of AlN is used to evaluate the nitrogen conversion ratio, which indicates the fraction of nitrogen converted from $\mathrm{BN}$ to $\mathrm{AlN}$.

\section{Results}

To begin with, a differential scanning calorimeter (DSC) analysis of the $[\mathrm{Al}+\mathrm{BN}(10 \mu \mathrm{m})]$ preform was carried out. Figure 2 shows the DSC curve of the $[\mathrm{Al}+\mathrm{BN}]$ preform together with the results obtained from monolithic powders. An endothermic peak at $933 \mathrm{~K}$ in the monolithic aluminum data exhibits a phase transformation (Al(solid) $\rightarrow$ $\mathrm{Al}$ (liquid)). No clear peaks are observed within this temperature range for the monolithic $\mathrm{BN}$ powder. A broad exothermic peak is found at around $1150 \mathrm{~K}$ from the $[\mathrm{Al}+\mathrm{BN}]$ preform. From this result, it is obvious that the 
(a)

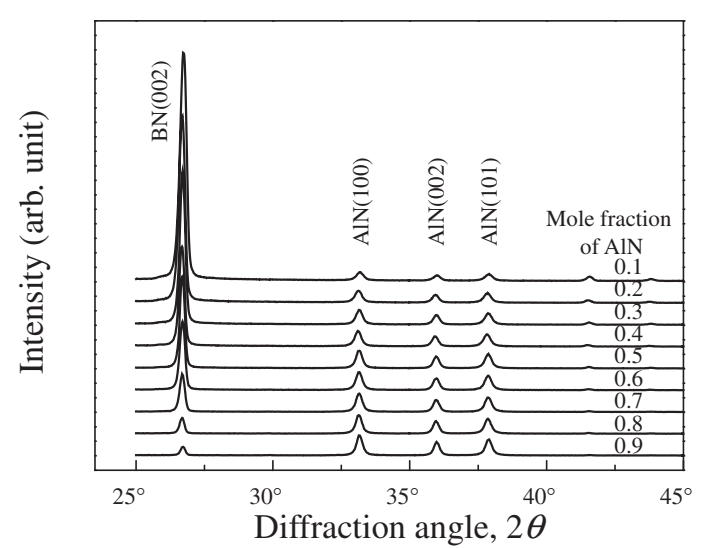

(b)

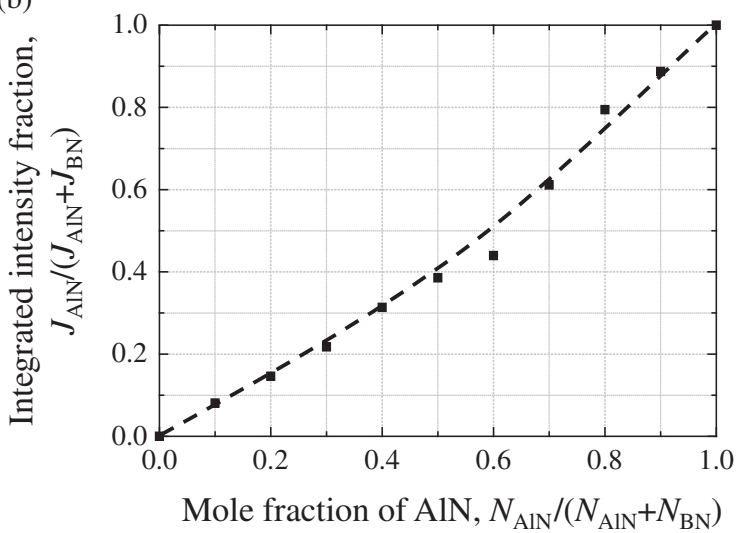

Fig. 1 (a) XRD data of blended powders consisting of $\mathrm{Al}$ and $\mathrm{BN}$ and (b) calibration curve derived from XRD data.

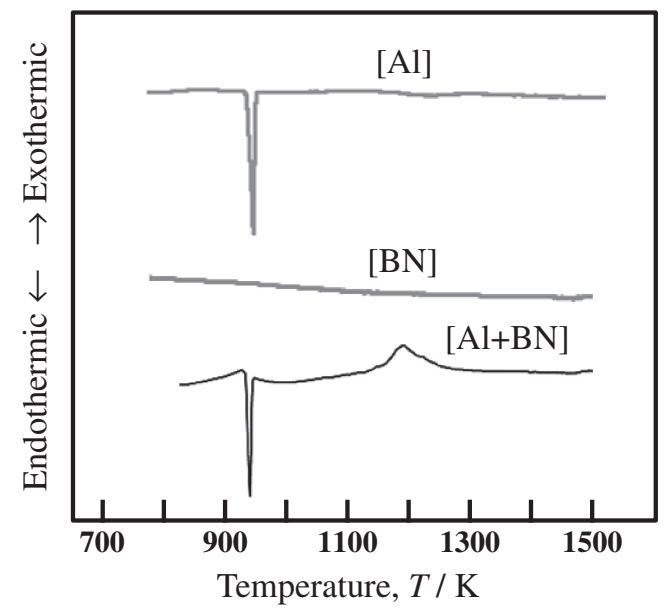

Fig. 2 Differential thermal analysis curves of aluminum, $\mathrm{BN}$ and $[\mathrm{Al}+\mathrm{BN}]$ powders (BN powder size: $10 \mu \mathrm{m})$.

exothermic reaction starts at a temperature between 1073 and $1173 \mathrm{~K}$.

Figure 3 shows the XRD data obtained from the $[\mathrm{Al}+\mathrm{BN}(10 \mu \mathrm{m})]$ preforms heated to temperatures ranging from 1073 to $1673 \mathrm{~K}$ (holding time: $0 \mathrm{~s}$ ). The AlN peak intensity increased and the $\mathrm{Al}$ peak intensity decreased with increasing heating temperature. As the reaction product, aluminum diboride $\left(\mathrm{AlB}_{2}\right)$, was detected at temperatures below $1273 \mathrm{~K}$. The following reaction might take place below $1273 \mathrm{~K}$ :

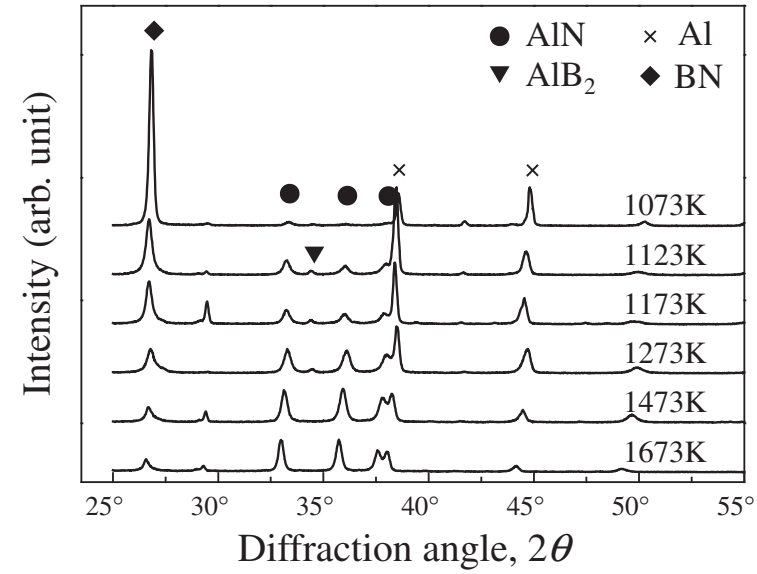

Fig. $3 \mathrm{XRD}$ data of $[\mathrm{Al}+\mathrm{BN}]$ preforms heated at $1073 \mathrm{~K} \sim 1673 \mathrm{~K}(\mathrm{BN}$ poder size: $10 \mu \mathrm{m}$, holding time: $0 \mathrm{~s}$ ).

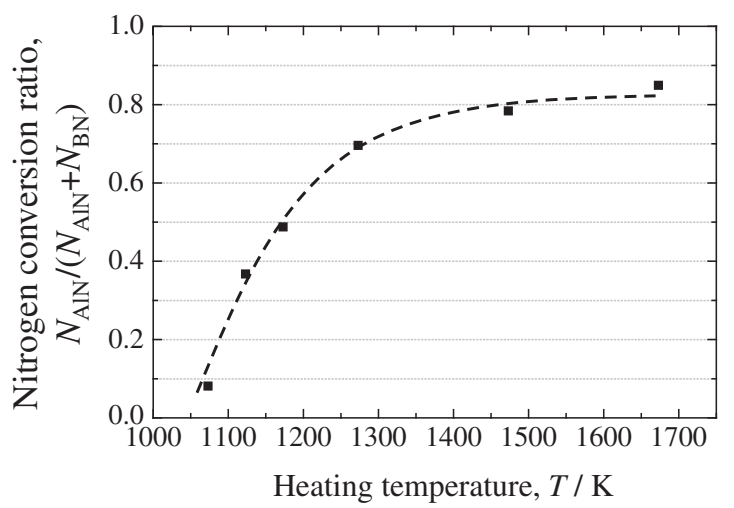

Fig. 4 Conversion ratio of $\mathrm{BN}$ to $\mathrm{AlN}$ as a function of heating temperature (BN powder size: $10 \mu \mathrm{m}$, holding time: $0 \mathrm{~s}$ ).

$$
3 \mathrm{Al}+2 \mathrm{BN} \rightarrow 2 \mathrm{AlN}+\mathrm{AlB}_{2}
$$

However, no $\mathrm{AlB}_{2}$ peaks were observed above $1473 \mathrm{~K}$. According to the Al-B phase diagram, $\mathrm{AlB}_{2}$ is not a stable phase at high temperatures and, therefore, decomposes as shown in the following equation.

$$
6 \mathrm{AlB}_{2} \rightarrow 5 \mathrm{Al}+\mathrm{AlB}_{12}
$$

D. Mirkovic et al. ${ }^{17)}$ reported the onset temperature of reaction (5) was $1275 \mathrm{~K}$ when the heating rate was $5 \mathrm{~K} \cdot \mathrm{s}^{-1}$, and the onset temperature increased with increasing the heating rate. This agrees well with the present results, in which no peaks of $\mathrm{AlB}_{2}$ are found at temperatures above $1473 \mathrm{~K}$. Although the $\mathrm{X}$-ray peak of $\mathrm{AlB}_{12}$ was not detected in this experiment, it might be present as reported by $\mathrm{Y}$. Seimiya. ${ }^{18)}$ The reason why $\mathrm{AlB}_{12}$ was not detected in this experiment is uncertain.

The integrated intensity of the $\mathrm{AlN}$ and $\mathrm{BN}$ peaks were measured, and the nitrogen conversion ratio was estimated as shown in Fig. 4. The conversion ratio was not high $(\sim 50 \%)$ when the heating temperature was below $1173 \mathrm{~K}$ and increased to more than $70 \%$ by increasing the heating temperature above $1273 \mathrm{~K}$.

The nitrogen conversion ratio as a function of the holding time is shown in Fig. 5. It is apparent that the nitrogen 


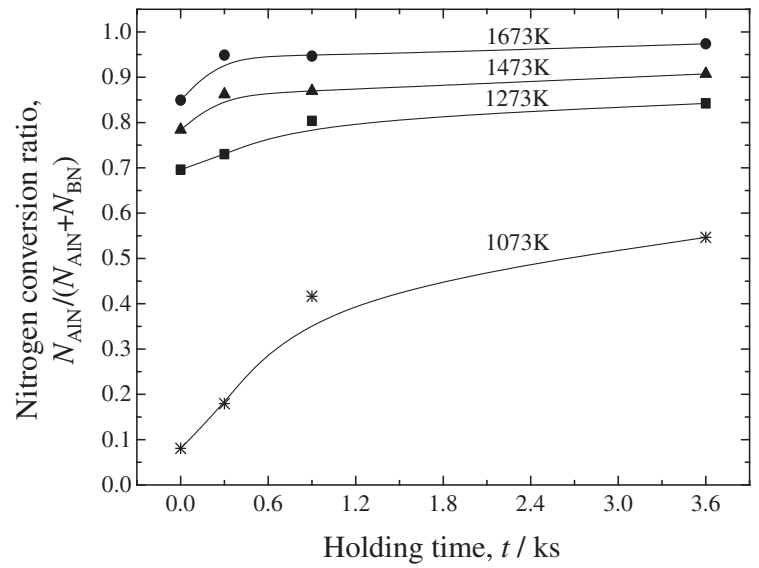

Fig. 5 Effect of holding time on nitrogen conversion ratio at temperatures ranging from $1073 \mathrm{~K}$ to $1673 \mathrm{~K}(\mathrm{BN}$ powder size: $10 \mu \mathrm{m})$.

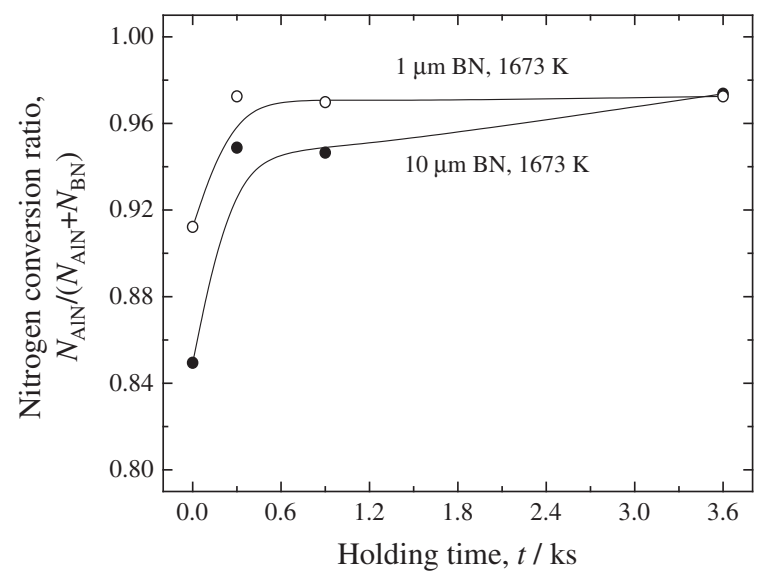

Fig. 6 Effect of BN powder size on nitrogen conversion ratio at $1673 \mathrm{~K}$.

conversion ratio can be increased by increasing the heating temperature and the holding time. As much as $95 \%$ of the nitrogen was converted from $\mathrm{BN}$ to $\mathrm{AlN}$ by heating the specimen for $3.6 \mathrm{ks}$ at $1673 \mathrm{~K}$. However, the conversion ratio seemed to saturate for the holding time of $3.6 \mathrm{ks}$, and probably would not be improved drastically by only increasing the holding time. These data agree with the results shown in previous research, ${ }^{16)}$ in which the conversion of $\mathrm{BN}$ to $\mathrm{AlN}$ and $\mathrm{TiB}_{2}$ was not increased by increasing the holding time from 3.6 to $10.8 \mathrm{ks}$.

From the results above, the nitrogen conversion ratio was shown to increase by increasing the heating temperature. However, the motivation of this study is to develop an energy saving process for producing $\mathrm{TiB}_{2} / \mathrm{AlN}$ composites, and therefore, it is undesirable to raise the heating temperature. Thus, the effect of reducing the $\mathrm{BN}$ powder size on the nitrogen conversion ratio was investigated. The nitrogen conversion ratio was evaluated by using a fine $\mathrm{BN}$ powder (average size: $1 \mu \mathrm{m}$ ). The results are shown in Fig. 6. It is clear that the nitrogen conversion ratio is improved by using the $1 \mu \mathrm{m}$ BN powder instead of the $10 \mu \mathrm{m}$ BN powder at both
$1473 \mathrm{~K}$ and $1673 \mathrm{~K}$. In particular, when the holding time is $300 \mathrm{~s}$ or less, the effect is significant. Therefore, it is expected that both the heating temperature and the holding time can be shortened when using fine BN powders. The authors are currently attempting further refinement of BN powders to a nano-order level by a mechanical milling process and intend to investigate the effects for reducing the synthesis temperature of AlN matrix composites.

\section{Summary}

(1) As a result of the DSC analysis, a broad exothermic peak was found at around $1150 \mathrm{~K}$ from the $[\mathrm{Al}+\mathrm{BN}]$ preform.

(2) The nitrogen conversion ratio was not sufficient $(\sim 50 \%)$ when the heating temperature was below $1173 \mathrm{~K}$. The conversion ratio was increased by increasing the heating temperature. As much as $95 \%$ of the nitrogen was converted from $\mathrm{BN}$ to $\mathrm{AlN}$ by heating at $1673 \mathrm{~K}$.

(3) The conversion ratio seemed to saturate with the holding time of $3.6 \mathrm{ks}$. This result agrees well with the data shown in previous research, in which the conversion of $\mathrm{BN}$ to $\mathrm{TiB}_{2}$ and $\mathrm{AlN}$ did not increase by increasing the heating time from 3.6 to $10.8 \mathrm{ks}$.

(4) The nitrogen conversion ratio was improved by using $1 \mu \mathrm{m} \mathrm{BN}$ powder instead of the $10 \mu \mathrm{m} \mathrm{BN}$ powder. When the holding time was $300 \mathrm{~s}$ or less, this effect was significant.

\section{REFERENCES}

1) G. Maranzana, I. Perry, D. Maillet and S. Rael: Int. J. Thermal Sci. 43 (2004) 21-29.

2) M. Medraj, Y. Baik, W. T. Thompson and R. A. L. Drew: J. Mater. Process. Tech. 161 (2005) 415-422.

3) A. F. Junior and D. J. Shanafield: Cerâmica 50 (2004) 247-253.

4) A. Maghsoudipour, M. A. Bahrevar, J. G. Heinrich and F. Moztarzadeh: J. Europ. Ceram. Soc. 25 (2005) 1067-1072.

5) Y. Baik and R. A. L. Drew: Key Eng. Mater. 122-124 (1996) 553-570.

6) Y. Baik and R. A. L. Drew: Key Eng. Mater. 122-124 (1996) 553-570.

7) L. M. Sheppard: Am. Ceram. Bull. 69 (1990) 1801-1812.

8) K. Komeya, A. Tsuge and A. Inoue: Mater. Sci. Lett. 1 (1982) 325-326.

9) K. Komeya, H. Inoue and A. Tsuge: Yogyo-Kyokai-Shi 89 (1981) 330-336.

10) S. Burkhardt, R. Riedel and G. Muller: J. Europ. Ceram. Soc. 17 (1997) 3-12.

11) W. A. Zdaniewski: Acta Metal. 37 (1989) 2313-2320.

12) X. Y. Zhang, S. H. Tan and D. L. Jiang: Ceram. Int. 31 (2005) 267-270.

13) M. Kobashi and T. Choh: J. Mater. Sci. 32 (1997) 6283-6289.

14) M. Kobashi, N. Tonokura and T. Choh: J. Japan Inst. Light Met. 46 (1996) 638-643.

15) M. Kobashi, T. Ohura and T. Choh: J. Japan Inst. Light Met. 45 (1995) 397-402.

16) M. Kobashi, K. Saiki and N. Kanetake: J. Japan Inst. Metals 75 (2011) printing.

17) D. Mirkovic, J. Grobner, R. Schmid-Fetzer, O. Fabrichnaya and H. L. Lukas: J. Alloy. Compd. 384 (2004) 168-174.

18) Y. Seimiya, K. Onodera, T. Yamaguchi and T. Shinoda: J. Japan Inst. Light Met. 57 (2007) 405-410. 